\title{
USINAGEM DA MADEIRA DE BRACATINGA PARA USO NA INDÚSTRIA MOVELEIRA
}

\author{
Esoline Helena Cavalli Zamarian'1, Carlos Eduardo Camargo de Albuquerque², \\ Jorge Luis Monteiro de Matos ${ }^{2}$ \\ 1Designer, M.Sc., SENAI, Curitiba, PR, Brasil - esoline.zamarian@pr.senai.br \\ 2Eng. Florestal, Dr., Depto. de Engenharia e Tecnologia Florestal, UFPR, Curitiba, PR, Brasil - camargo@ufpr.br; jmatos@ufpr.br \\ Recebido para publicação: 21/06/2009 - Aceito para publicação: 04/04/2012
}

\begin{abstract}
Resumo
Este trabalho teve como objetivo avaliar o comportamento da madeira de bracatinga (Mimosa scabrella Benth.) quanto à trabalhabilidade para ser empregada no setor moveleiro, com amostras oriundas de plantios com 7 a 9 anos. Os vinte e cinco corpos de prova foram usinados e submetidos a uma avaliação qualitativa orientada pela norma ASTM D1666 (1994). Nas operações de desempeno, desengrosso, furação para dobradiça e rasgo com furadeira horizontal, obtiveram-se índices de aproveitamento de peças acima de $92 \%$, revelando o potencial da madeira de bracatinga para o uso em móveis. Embora as condições de corte e do material tenham influenciado nas operações de moldura axial e sinuosa e de fresagens axial e transversal, que, respectivamente, tiveram $32 \%, 40 \%$ e $48 \%$ de peças aprovadas, não desqualificam a madeira para essas operações, apenas indicam a necessidade de um posterior lixamento nessas superfícies. Considerando que a pouca idade do material estudado favoreceu resultados adequados para a finalidade do estudo, acredita-se que a madeira de bracatinga pode obter resultados ainda mais promissores para a trabalhabilidade da madeira provinda de plantios manejados e com idades acima de 12 anos.

Palavras-chave: Bracatinga (Mimosa scabrella Benth.); design; mobiliário; processamento da madeira.
\end{abstract}

\begin{abstract}
Bracatinga wood machining for furniture industry. This research aimed to evaluate suitability of bracatinga (Mimosa scabrella Benth.) wood for furniture industry, with samples from 7 to 9 years old plantations. The twenty five specimens selected were machined and subjected to a qualitative assessment accordingly to ASTM D1666 (1994). In unbending operations, thicknessing, drilling to hinge and tear with horizontal drilling, excellent results have been obtained, revealing the potential of bracatinga wood for furniture purposes (recovery of over than $92 \%$ of parts). Even though the cutting conditions and material have influenced the operations of axial and sinuous frame, and axial and transversal milling, which reached respectively $32 \%, 40 \%$ and $48 \%$ of approved parts, the wood does not disqualify for these operations, it only indicates the need of a subsequent grinding of these surfaces. Whereas the young age of the studied material favored adequate results for the purpose of the study, it allows to believe that bracatinga wood more promising results are those from handled planting older than the ones focused.
\end{abstract}

Keywords: Bracatinga (Mimosa scabrella Benth.); design; furniture; wood process.

\section{INTRODUÇÃO}

Os usos atribuídos à madeira da bracatinga são direcionados para atividades com pouco retorno comercial, destacando-se apenas para fins energéticos (CARVALHO, 2003). Empresa Brasileira de Pesquisa Agropecuária (EMBRAPA, 1988) descreve que o insucesso comercial do mobiliário de bracatinga deve-se à relutância do mercado em aceitar uma espécie nova de madeira. No entanto, para uma boa produtividade em madeira, recomenda-se um tratamento silvicultural, principalmente na fase inicial do plantio (CARPANEZZI, 2004).

A madeira de bracatinga não possui cerne e alburno distintos pela cor, seu brilho é pouco acentuado e a cor varia de castanho-acinzentado a castanho-rosado. A grã é direita e a textura é 
considerada média, com diâmetros tangenciais dos poros de 100 a $190 \mu \mathrm{m}$ (UFPR, 1979). Os anéis de crescimento são distintos, individualizados por zonas fibrosas tangenciais mais escuras e também em certas regiões por parênquima marginal. As camadas de crescimento são delimitadas por fibras de paredes mais espessas e achatadas (MANIERI; CHIMELO, 1989).

A madeira de bracatinga é moderadamente densa $\left(0,65\right.$ a $0,81 \mathrm{~g} / \mathrm{cm}^{3}$ entre $12 \%$ e $15 \%$ de umidade), possui limite de resistência à compressão axial de $545 \mathrm{kgf} / \mathrm{cm}^{2}$ e limite de resistência à flexão estática de $982 \mathrm{kgf} / \mathrm{cm}^{2}$. A madeira é difícil de cortar, fácil de aplainar e lixar, obtendo superfície lisa. A bracatinga é considerada de baixa durabilidade, porém é permeável às soluções preservantes (CARVALHO, 2003; IPT, 2003; UFPR, 1979).

Para um bom aproveitamento da madeira de bracatinga, o programa de secagem deve ser suave $\left(60{ }^{\circ} \mathrm{C}\right)$, com tempo de secagem de sete dias, para que a perda da umidade transcorra de maneira regular. Isso se deve à facilidade de a madeira rachar, empenar e colapsar (KLITZKE, 2006).

As atividades de transformação da madeira nas fábricas de móveis caracterizam-se por operações como o destopo, o aplainamento, o corte, a fresagem e as furações. A sequência varia de acordo com a rotina da empresa, da estrutura do produto, do modelo de organização (layout) e da programação definida, mediante a capacidade produtiva e dos recursos disponíveis (LUCAS, 2004).

$\mathrm{O}$ conhecimento das propriedades e do comportamento da madeira durante a usinagem é de fundamental importância para a correta utilização de espécies na fabricação de móveis (LUCAS, 2004). No entanto deve-se considerar a utilização correta dos maquinários e de ferramentas, para garantir a competitividade no setor moveleiro e a qualidade resultante do processo. Para isso, os valores definidos para a correlação processo e qualidade, segundo Bonduelle (2001), normalmente são definidos pelo tempo e número de manutenções das ferramentas de corte envolvidas.

Nesse sentido, o objetivo deste trabalho é avaliar o comportamento da madeira de bracatinga quanto à trabalhabilidade para ser empregada no setor moveleiro.

\section{MATERIAL E MÉTODOS}

A madeira selecionada para o estudo da usinagem da bracatinga foi proveniente de plantios com 7 a 9 anos de idade, com produtores parceiros da Agência de Desenvolvimento da Mesorregião Vale do Ribeira/Guaraqueçaba e Instituto Paranaense de Assistência Técnica e Extensão Rural (Emater).

A madeira foi seca conforme o programa apresentado por Klitzke (2006), para peças com $26 \mathrm{~mm}$ de espessura. O material foi pré-cortado nas medidas 122 × 626 × $18 \mathrm{~mm}$, e 25 tábuas foram classificadas evitando-se áreas de podridão, nós, rachaduras ou defeitos de secagem (Figura 1).

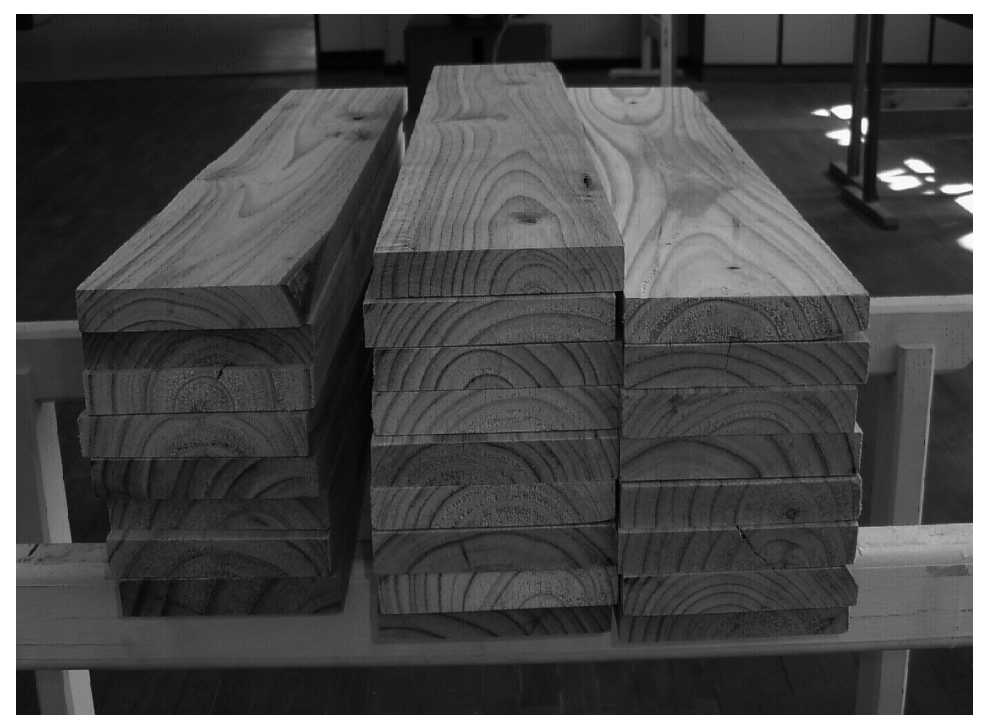

Figura 1. Madeira selecionada para os testes de usinagem.

Figure 1. Wood selected for machining tests. 
Para as medições dos parâmetros utilizados na usinagem, utilizou-se cronômetro digital, paquímetro digital, transferidor e escalímetro. Para coletar os dados, foram usadas fichas de avaliação para as operações de usinagem, seguindo o critério de pontuação baseado na norma ASTM D1666-87 (1994) de análise qualitativa.

Para a realização dos ensaios, verificou-se o teor de umidade em $13 \%$ com medidor elétrico. Com base na orientação da norma ASTM D166-87 (1994), foram adaptados e executados os testes de usinagem que envolvem as operações de desempeno, desengrosso, moldura no topo, moldura axial sinuosa com faca plana, rasgo na furadeira horizontal, moldura axial e transversal e furações para cavilha e dobradiça (Figura 2).

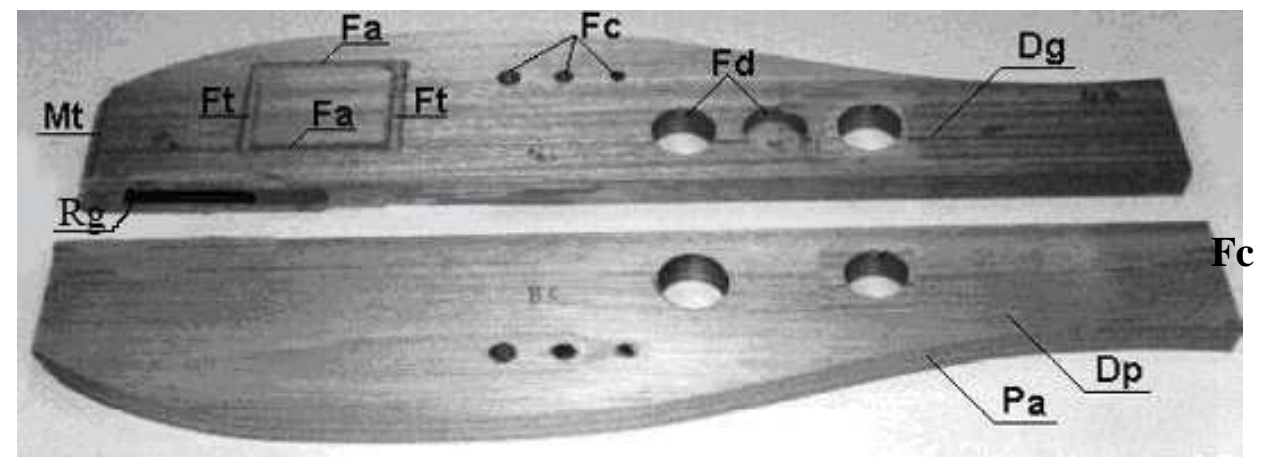

Figura 2. Corpo de prova dos ensaios de usinagem: Dp: desempeno; Dg: desengrosso; Mt: moldura no topo; Pa: moldura axial sinuosa (com faca plana); Rg: rasgo na furadeira horizontal; Fa: fresamento axial; Ft: fresamento transversal; Fc: furação para cavilha; Fd: furação para dobradiça.

Figure 2. Test mold for machining tests. Dp: Dg: rough tooling; Mt: top cover; Pa: axial curves (plain cutter); Rg: rip on horizontal drill; Fa: axial milling; Ft: horizontal milling; Fc: pin drill; Fd: hinge drill.

Para evitar variações mecânicas, confeccionaram-se gabaritos para o correto posicionamento de cortes e furações, assim como usinagens experimentais para estabelecer velocidades de avanço, regulagens de ferramentas de corte e da rotação do motor, a fim de avaliar todas as peças em condições de similaridade.

Na tabela 1 relacionam-se os parâmetros adotados conforme a operação realizada e as variáveis que interferem no processo de usinagem.

Tabela 1. Parâmetros utilizados na execução dos testes de usinagem de bracatinga.

Table1. Parameters used on bracatinga machinery try-outs.

\begin{tabular}{lcccccc}
\hline Operação & $\mathbf{Z}\left(\mathbf{n}^{\mathbf{0}}\right)$ & $\mathbf{n}\left(\mathbf{m i n}^{-\mathbf{1}}\right)$ & $\mathbf{D}(\mathbf{m m})$ & $\mathbf{V c}(\mathbf{m} / \mathbf{s})$ & $\mathbf{V} \boldsymbol{f}(\mathbf{m} / \mathbf{m i})$ & $\boldsymbol{f \mathbf { z }}$ \\
\hline Desempeno & 4 & 5000 & 120 & 31,4 & 7,99 & 0,40 \\
Desengrosso & 4 & 5000 & 120 & 31,4 & 4,53 & 0,23 \\
Moldura no topo & 2 & 9000 & 120 & 56,5 & 2,46 & 0,14 \\
Moldura axial sinuosa & 4 & 9000 & 85 & 40,0 & 3,86 & 0,11 \\
Rasgo na furadeira horizontal & 2 & 3380 & 8 & 1,4 & 3,25 & 0,48 \\
Fresagem & 1 & 18000 & 8 & 7,54 & 5,09 & 0,28 \\
Furação cavilha & 2 & 2776 & $6 ; 8 ; 10 ; 12$ & 0,$87 ; 1,16 ; 1,45 ; 1,74$ & 0,4 & 0,07 \\
Furação dobradiça & 2 & 2700 & 35 & 4,94 & 0,15 & 0,03
\end{tabular}

Z: número de gumes da ferramenta de corte; n: frequência de rotação do eixo; D: diâmetro da ferramenta; Vc: velocidade de corte; Vf: velocidade de avanço; fz: avanço por dente.

Para a análise da qualidade da usinagem, definiram-se critérios subjetivos, mediante a apreciação de três avaliadores experientes técnicos do Serviço Nacional de Aprendizagem Industrial (Senai), que 
atribuíram, isoladamente, notas às amostras apresentadas para cada operação realizada, sem que para isso existisse um modelo em uma espécie de madeira predefinida como parâmetro. Em todas as operações, as notas um, dois, três, quatro e cinco, equivalem, respectivamente, às conceituações excelente, bom, regular, ruim e péssimo, segundo a ASTM D1666 (1994). São consideradas aptas para serem usadas no setor moveleiro as peças que obtiverem conceito excelente e bom.

A avaliação da qualidade de acabamento realizou-se contando-se o número de marcas deixadas pelas facas contidas em uma polegada (os valores coletados foram obtidos por média aritmética em amostras selecionadas ao acaso), a fim de correlacionar com a velocidade de avanço por dente.

Com essa informação foi possível comparar os valores obtidos com os padrões sugeridos no estudo realizado por Bonduelle (2001), para a melhor relação de qualidade do processo de usinagem.

As operações de desempeno e desengrosso foram executadas em plainas desempenadeira e desengrossadeira. As notas foram atribuídas em função da rugosidade da superfície trabalhada e variavam de 1 a 5 , sendo 1 a nota que equivale à superfície isenta de defeitos e cinco à da superfície com arrancamento forte de material lenhoso e arrepiamento forte de fibras, comprometendo totalmente a qualidade da usinagem.

A operação de moldura no topo foi realizada em tupia de mesa com faca perfilada transversalmente à grã. As notas compreendiam valores de $1 \mathrm{a} 5$, sendo 1 a nota equivalente à superfície isenta de defeitos e com o perfil completo e 5 a nota equivalente à superfície com arrancamento e arrepiamento forte de fibras, com perfil incompleto, comprometendo totalmente a qualidade da usinagem.

Após a realização de um pré-corte na serra fita, fez-se a moldura axial sinuosa com faca plana na tupia de mesa, trocando-se a ferramenta de corte. As notas de 1 a 5 foram atribuídas em função da presença de lasqueamentos, arrancamentos ou arrepiamento de fibras, principalmente na porção da curva contrária à orientação das fibras. A nota 1 equivale à superfície isenta de defeitos e 5 à superfície com presença de arrepiamento e arrancamento forte de fibras.

A furação para cavilhas foi realizada em furadeira múltipla, realizando-se três furos passantes, com 8,10 e $12 \mathrm{~mm}$, e outros três furos idênticos, com profundidade de $15 \mathrm{~mm}$. A furação de topo foi realizada com broca de $10 \mathrm{~mm}$ no plano horizontal, com $21 \mathrm{~mm}$ de profundidade. As notas de 1 a 5 foram atribuídas conforme a qualidade da superfície de entrada e de saída da broca. A nota 1 equivale à ausência de defeitos e contornos perfeitos em todos os furos e a nota 5 à presença de lasqueamento e arrepiamento de fibras na maioria dos furos.

A furação para dobradiça foi realizada em furadeira vertical. Foram executadas três furações, sendo uma passante. As notas foram atribuídas em conjunto, tendo em vista a qualidade de entrada e saída da broca, principalmente na furação passante (SILVA, 2002). As furações receberam notas de 1 a 5 , considerando o grau de arrancamento de fibras e tamanho da área afetada.

$\mathrm{O}$ rasgo na furadeira horizontal foi avaliado em função do levantamento de fibras presentes em quaisquer partes das bordas ou do fundo do rasgo. As notas variaram de 1 a 5 conforme a quantidade de fibras levantadas presentes em qualquer uma das superfícies em contato com a ferramenta de corte, sendo 1 a nota equivalente à ausência de defeitos na operação e 5 a presença de lasqueamento e arrepiamento de fibras ao longo do canal.

A fresagem foi realizada na tupia superior, executando canais axiais e transversais sobre a superfície trabalhada. A ferramenta de corte escolhida possui $8 \mathrm{~mm}$ de diâmetro, realizando um corte de 6 $\mathrm{mm}$ de profundidade. As notas atribuídas variaram de 1 a 5, analisando-se a presença de lasqueamentos e arrepiamentos de fibras ao longo dos canais executados, sendo a nota 1 a ausência de defeitos em qualquer uma das arestas de corte e 5 a presença de fibras arrancadas e arrepiadas em grau forte ao longo de todo o canal.

Após a realização dos testes, as amostras foram avaliadas separadamente, obtendo-se os dados para análise da qualidade da madeira na usinagem. Os corpos de prova, após avaliação, tiveram uma das superfícies lixada com grão 180, a qual recebeu uma demão de fundo acabamento transparente de base poliuretânica F040 6741 (SAYERLACK) diluído com DF 4068 (SAYERLACK) e catalisado com FC6964 (SAYERLACK) a 30\%. Após secagem de 3 horas, as superfícies foram lixadas com lixa de grão 320 e receberam a segunda demão do mesmo tratamento (Figura 3).

Como os resultados da usinagem possuem relação com a densidade da madeira, realizou-se um modelo virtual semelhante ao corpo de prova, considerando todas as operações de usinagem, no software de modelamento 3D (Solid Works), definindo-se o volume de $897,18 \mathrm{~cm}^{3}$ constante para todas as 
amostras. O peso foi coletado com o uso de balança digital, obtendo-se assim as densidades individuais dos corpos de prova usinados.

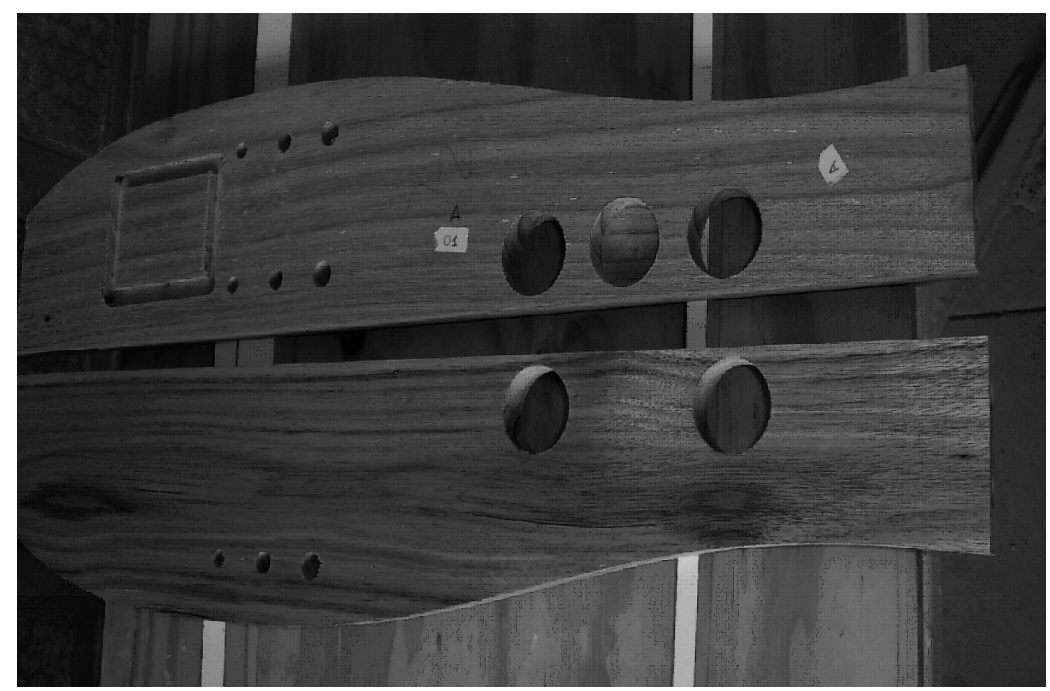

Figura 3. Corpos de prova com uma das faces com acabamento superficial.

Figure 3. Test molds with superficial finishing.

Como o objetivo do estudo é avaliar a classificação atribuída à qualidade da usinagem, optou-se por uma avaliação qualitativa e quantitativa em termos percentuais, por meio de gráficos processados pelo programa Microsoft Excel.

\section{RESULTADOS E DISCUSSÃO}

Para melhor apresentar o desempenho da madeira de bracatinga nas operações de usinagem, somaram-se os percentuais dos conceitos 1 e 2 das peças avaliadas para definir a sua aprovação.

$\mathrm{O}$ resultado da operação de desempeno revelou que a madeira de bracatinga obteve excelente aprovação na operação avaliada, totalizando $96 \%$ de peças aprovadas.

Comparando os parâmetros adotados para a operação de desempeno, o avanço por dente deve estar num intervalo de $1 \mathrm{~mm}<f z<1,8 \mathrm{~mm}$, a fim de se obter a melhor relação qualidade versus desgaste, percebendo-se que as amostras estudadas estão com um padrão de qualidade adequado para a vida útil do gume (BONDUELLE, 2001).

$\mathrm{O}$ desempenho da madeira de bracatinga no teste de desengrosso revelou que a totalidade das peças foi aprovada, indicando o excelente desempenho dessa madeira para a operação de desengrosso e a boa adequação do maquinário e das ferramentas usadas no corte. O valor do avanço por dente obtido reflete a excelente qualidade de superfície, com base nos parâmetros adotados (BONDUELLE, 2001).

A madeira de bracatinga, na operação de moldura no topo, atingiu $32 \%$ de peças aprovadas. Os parâmetros usados durante a operação de moldura no topo estão dentro dos valores propostos pela relação velocidade de avanço, quantidades de facas $\mathrm{x}$ rotação e comprimento do passo, sugeridos na literatura (LEITZ, 2001). A velocidade de corte, no entanto, ficou abaixo de $60 \mathrm{~m} / \mathrm{s}$, recomendada por Bonduelle (2001). A incisão das fibras realizada por velocidades de corte mais altas reduz o arrancamento das fibras. Contudo, deve-se controlar a velocidade para não escurecer a superfície de corte, fato que reduz a qualidade da usinagem.

Acredita-se que, para a operação de moldura no topo, a pouca homogeneidade do material lenhoso relativo à distância entre os anéis de crescimento e a baixa massa específica da madeira na região da medula, em algumas amostras, justificam o baixo desempenho nas análises, uma vez que amostras com maior densidade receberam melhor pontuação na avaliação, conforme a tabela 2.

O material das facas high speed steel (HSS) (aço rápido) também pode influenciar na perda da velocidade de corte e, consequentemente, na qualidade final da usinagem. 
Tabela 2. Densidade média dos corpos de prova na somatória dos conceitos para a operação de moldura no topo.

Table 2. Average density of test molds in the sum of concepts for the frame operation of the top.

\begin{tabular}{lcc}
\hline Densidade média $\left(\mathbf{g} / \mathbf{c m}^{3}\right)$ & Notas & Conceitos \\
\hline 0,713 & 1 e 2 & Excelente e bom \\
0,671 & 3 & Regular \\
0,601 & 4 e 5 & Ruim e péssimo \\
\hline
\end{tabular}

A velocidade de avanço foi definida em função da rotação do motor, visto que a passagem mais lenta da peça durante o corte resultaria em peças com melhor acabamento, porém com ocorrências de superfícies queimadas. Uma maior rotação também permitiria maior qualidade, porém não é seguro devido aos constantes contragolpes durante o processo. Para um melhor aproveitamento das peças, recomenda-se o lixamento posterior à usinagem, conforme o perfil da ferramenta de corte empregada. $\mathrm{O}$ lixamento é uma operação de rotina nas empresas que compensa as irregularidades da superfície usinada, mas, tecnicamente, é uma atividade que implica maior tempo de beneficiamento da madeira, além de comprometer a precisão dimensional das peças (SILVA, 2002).

$\mathrm{Na}$ operação de moldura axial sinuosa, $40 \%$ das peças usinadas foram aprovadas no teste. A velocidade de corte durante o teste para a moldura sinuosa foi menor do que a velocidade sugerida por Bonduelle (2001), fato que reduz a qualidade.

Os ensaios de furação para cavilha geraram $48 \%$ de peças aprovadas. Contudo, de maneira geral, o processo de furação não apresentou rejeitos ou imperfeições, como, por exemplo, a presença de arrancamento de fibras na superfície de topo em relação à broca na saída da ferramenta. Segundo Lucas (2004), o processo de usinagem que causa a menor restrição de qualidade, como também os menores índices de manutenção ou trocas de ferramentas, é a furação.

No teste de furação para dobradiça, $92 \%$ das peças foram aprovadas, mostrando que a madeira de bracatinga possui bom desempenho para a operação analisada, bem como as boas condições do maquinário empregado.

Para o teste de rasgo na furadeira horizontal, $96 \%$ das peças foram aprovadas, mostrando o bom desempenho da madeira de bracatinga para a operação, bem como as boas condições de equipamento e ferramenta de corte. Na operação rasgo com furadeira horizontal, os parâmetros adotados também revelaram um avanço por dente condizente com o proposto por Leitz (2001).

A operação de fresagem foi avaliada agrupando-se as fresagens axial e transversal, obtendo-se $48 \%$ de peças aprovadas. No entanto, cabe ressaltar que, durante a execução do teste, observou-se que a qualidade da usinagem na operação de fresagem em tupia superior está relacionada com a habilidade do operador em controlar o avanço da ferramenta de corte, pois este não tem controle mecânico ou automatizado. Essa condição do equipamento pode propiciar o aparecimento de áreas queimadas. No entanto, mesmo o avanço sendo manual, o avanço por dente calculado está acima do intervalo de $0,10 \mathrm{~mm}<f z<0,20 \mathrm{~mm}$ para as operações de fresamento frontal, sugerido por Bonduelle (2001), resultando em perda da qualidade. Durante o processo, verificou-se que a fresagem transversal é a operação que mais revela o aparecimento de fibras com grau elevado de arrepiamento. Essa relação está associada à variação de densidade no sentido do corte, que apresenta menos homogeneidade no material lenhoso relativo à distância entre os anéis de crescimento. Avaliando separadamente os corpos de prova, percebeu-se que amostras mais pesadas recebiam as melhores pontuações na operação estudada, logo, acredita-se que uma maior densidade elevaria o número de peças aprovadas, conforme mostra a tabela 3.

Tabela 3. Densidade média dos corpos de prova na somatória dos conceitos para a operação de fresagem.

Table 3. Average density of test molds in the sum of concepts for the milling operation.

\begin{tabular}{lcc}
\hline Densidade média $\left(\mathbf{g} / \mathbf{c m}^{3}\right)$ & Notas & Conceitos \\
\hline 0,687 & 1 e 2 & Excelente e bom \\
0,635 & 3 & Regular \\
0,602 & 4 e 5 & Ruim e péssimo \\
\hline
\end{tabular}

O processo de acabamento não foi submetido à avaliação de aderência de verniz, apenas serviu de base para constatar que a madeira de bracatinga possui comportamento normal para esse item, segundo a avaliação dos profissionais. 
Silva (2002) avaliou o desempenho da madeira da espécie Eucalyptus grandis de diferentes idades para o uso em móveis, concluindo que a espécie, de modo geral, tem um bom desempenho na usinagem para as 15 amostras avaliadas. No entanto, a madeira com 20 e 25 anos formou o grupo de maior número de peças aprovadas e com melhor desempenho. Nesse sentido, a tabela 4 traz a porcentagem de peças aprovadas na usinagem da espécie Eucalyptus grandis com 10 anos de idade, segundo Silva (2002), e da bracatinga com 7 a 9 anos de idade, visando levantar um comparativo entre as espécies para cada operação realizada. Embora o quadro tenha apenas função ilustrativa, recomenda-se realizar estudos de usinagem com madeira de bracatinga de diferentes idades, para levantamento de dados comparativos do desempenho das espécies sob as mesmas condições de ensaios e, assim, verificar as diferenças estatísticas.

Tabela 4. Número de peças aprovadas da madeira de eucalipto e de bracatinga na usinagem.

Table 4. Number approved of pieces of Eucalyptus and bracatinga wood during machining.

\begin{tabular}{lcc}
\hline \multirow{2}{*}{ Operação } & \multicolumn{2}{c}{$\mathbf{N}^{\mathbf{0}}$. de peças aprovadas (\%) } \\
\cline { 2 - 3 } & Eucalyptus grandis * & Mimosa scabrella \\
\hline Aplainamento & 68 & 98 \\
Moldura no topo & - & 32 \\
Moldura sinuosa & 47 & 40 \\
Furação para cavilha & 72 & 48 \\
Furação para dobradiça & - & 92 \\
Rasgo em furadeira horizontal & 92 & 96 \\
Fresagem & 40 & 48 \\
\hline
\end{tabular}

* Silva (2002).

A qualidade da madeira também é influenciada pelo fator idade, conforme mostra o estudo de Silva (2002) com madeira de Eucalyptus grandis. A madeira de bracatinga com 12 a 15 anos pode oferecer material de alta qualidade, a exemplo da madeira proveniente de plantio manejado em Bituruna (12 anos), que garantiram a trabalhabilidade da madeira na construção de móveis, revelando a importância do trato silvicultural para a qualidade da madeira serrada (Figura 4).

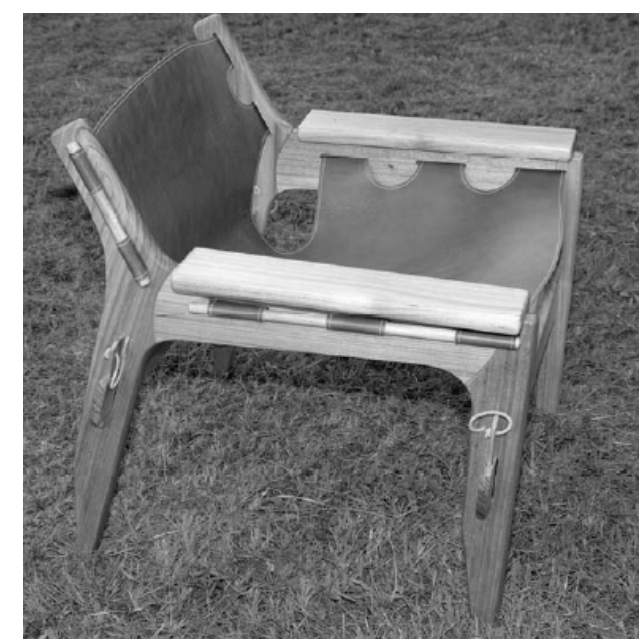

Figura 4. Móvel produzido em madeira de bracatinga com 12 anos de idade.

Figure 4. A 12 years old furniture made of bracatinga wood.

\section{CONCLUSÕES}

- Diante dos resultados obtidos, pode-se concluir que a madeira de bracatinga está apta para ser utilizada na indústria moveleira. Atribuiu-se à espécie elevada conceituação, com índices acima de $92 \%$ de aprovação nas operações de desempeno, desengrosso, furação para dobradiça e rasgo com furadeira horizontal. 
- As operações de moldura de topo, moldura axial, furação para cavilhas e fresagem axial tiveram menos de $50 \%$ de peças aprovadas.

- A menor densidade, bem como a pouca homogeneidade nas camadas de crescimento interferem na qualidade da usinagem para as operações de corte transversais à grã.

- Através da avaliação da usinagem da bracatinga, percebe-se que a espécie tem potencialidade para a produção de móveis maciços e é de fácil trabalhabilidade.

\section{REFERÊNCIAS}

AMERICAN SOCIETY FOR TESTING AND MATERIALS. ASTM D 1666-87: Standard method for conducting machining tests of wood and wood base materials (revisada em 1994). Philadelphia. 1995.

BONDUELlE, A. Usinagem, qualidade e custo. Revista da Madeira, Curitiba, n. 61, p. 82 - 86, 2001.

CARPANEZZI, A. A. Aspectos técnicos da produção de bracatinga. In: OFICINA SOBRE BRACATINGA NO VALE DA RIBEIRA, 1, 2004, Curitiba. Anais... p. 20 - 23.

CARVALHO, P. E. R. Espécies arbóreas brasileiras. Colombo, PR: Embrapa Florestas, 2003.

EMPRESA BRASILEIRA DE PESQUISA AGROPECUÁRIA (EMBRAPA). Centro Nacional de Pesquisa de Florestas (Curitiba-PR). Manual técnico da bracatinga (Mimosa scabrella Benth.). Curitiba, 1988. 70 p. (EMBRAPA-CNPF. Documentos, 20).

INSTITUTO DE PESQUISAS TECNOLÓGICAS (IPT). Madeira: uso sustentável na construção civil. Coordenador Oswaldo Poffo Ferreira. São Paulo: Instituto de Pesquisas Tecnológicas: SVMA: Sinduscon - SP, 2003 - (Publicação IPT; 2980).

KLITZKE, R. J. Desenvolvimento de programa de secagem para madeira de Mimosa Scabrella (bracatinga) com 26 mm de espessura. Curitiba, 2006. 18 f. Relatório Parcial - FUPEF-Fundação de Pesquisas Florestais do Paraná.

LEITZ. THE LEITZ LEXICON. Handbook for woodworking machine tools. Co.KG, Oberkochen. Ed. 3, p. $11-18,2001$.

LUCAS, F. C. Análise da usinagem da madeira visando à melhoria de processos em indústrias de móveis. 176 f. Tese (Doutorado em Engenharia de Produção) - Universidade Federal de Santa Catarina, Florianópolis, 2004.

MANIERI, C.; CHIMELO, J. P. Ficha de características das madeiras brasileiras. São Paulo: IPT, 1989.

SILVA, J. C. Caracterização da madeira de Eucalyptus grandis Hill ex. Maiden, de diferentes idades, visando a sua utilização na indústria moveleira. $160 \mathrm{f}$. Tese (Doutorado em Engenharia Florestal) Setor de Ciências Agrárias, Universidade Federal do Paraná, Curitiba, 2002.

SILVA, J. R. M. Relações da usinabilidade e aderência do verniz com as propriedades fundamentais do Eucalyptus grandis Hill ex. maiden. 204 f. Tese (Doutorado em Engenharia Florestal) - Setor de Ciências Agrárias, Universidade Federal do Paraná, Curitiba, 2002.

UNIVERSIDADE FEDERAL DO PARANÁ (UFPR); Centro de Pesquisas Florestais. Estudos das alternativas técnicas, econômicas e sociais para o setor florestal do Paraná: subprograma tecnologia, relatório final. Curitiba: SUDESUL / IBDF, 1979. 